\title{
A low temperature, solution route to macroscopic amounts of hydrogen terminated silicon nanoparticles
}

\author{
Doinita Neiner, Hsiang Wei Chiu and Susan M. Kauzlarich* \\ Department of Chemistry, One Shields Ave, University of California, Davis, California 95616 \\ RECEIVED DATE (automatically inserted by publisher); E-mail: smkauzlarich@ucdavis.edu
}

\section{EXPERIMENTAL}

All manipulations for the synthesis of $\mathrm{Si}$ nanoparticles were performed in a $\mathrm{N}_{2}$ filled glove box or Ar inert atmosphere Schlenk line. The silicon nanoparticles were prepared by a solution reaction using sodium silicide and ammonium bromide in dimethoxyethane (DME) and dioctyl ether (DOE), Silicon (99.999\% Aldrich) and sodium (lump 99\% Aldrich) were used as received. Sodium silicide was prepared by reacting stoichiometric amounts of the elements in sealed niobium tubes, sealed in evacuated fused silica ampoules, heated at $650^{\circ} \mathrm{C}$ for 3 days. The $\mathrm{X}$-ray powder diffraction of the black solid product was consistent with the calculated powder diffraction pattern from the ICSD database. Ammonium bromide (99.99\% Aldrich) was dried under dynamic vacuum at $100{ }^{\circ} \mathrm{C}$ for 14 hours prior usage. DME was dried and degassed before using. DOE (99\% Aldrich) (boiling point $289{ }^{\circ} \mathrm{C}$ ) was dried by heating and stirring at $80{ }^{\circ} \mathrm{C}$ under dynamic vacuum overnight. Typically, $0.50 \mathrm{~g}$ of sodium silicide was stirred and heated at $60^{\circ} \mathrm{C}$ overnight in $200 \mathrm{ml}$ of solvent. The mixture, solvent and sodium silicide, was cannulated over in a Schlenk degassed flask containing $0.55 \mathrm{~g}$ ammonium bromide. The reaction flask was heated under flowing argon. The DME and DOE reactions were performed at $70-80{ }^{\circ} \mathrm{C}$ (b.p. DME $85{ }^{\circ} \mathrm{C}$ ) and $260-280{ }^{\circ} \mathrm{C}$ (b.p. DOE $289{ }^{\circ} \mathrm{C}$ ), respectively. The reaction was considered complete when evolution of ammonia gas ceased, as indicated by $\mathrm{pH}$ paper. Thus, the reaction times were 48 hours and 9-12 hours, for DME and DOE, respectively. After the reaction, a yellow (DOE) or brown-orange (DME) solution and a dark grey powder were present in the flask. The two products are separated by cannulating the mixture under vacuum/argon in an air free funnel connected to a round bottom flask. The whole setup, funnel and round bottom flask were maintained under inert atmosphere or vacuum at all times. The powder stays on the frit of the funnel and the liquid can be collected in the round bottom flask. In the DOE synthesis, the yellow liquid can be made into a brown powder $(0.0155 \mathrm{~g})$ by solvent evaporation. The powder was washed under argon by cannulating degassed warm acidified water $(\mathrm{HF} \sim 2 \%)$ over it to remove the salt byproduct, $\mathrm{NaBr}$. Then the material was rinsed with water and hexane and dried under vacuum for 4 hours. The yield in the powder product $(0.2 \mathrm{~g})$ was approximately 73 weight \%, assuming that all the NaSi was converted to $\mathrm{Si}$. The yields of material using DME as a solvent were similar.

\section{CHARACTERIZATION}

Transmission Electron Microscopy (TEM) and energydispersive X-ray (EDX) spectroscopy analysis of these NP were performed on a Philips CM-12, operating at $100 \mathrm{keV}$. In the case of the resulting yellow and brown-orange solutions (from DME and DOE), the TEM samples were prepared by dipping the holey, carbon coated 400-mesh grid in the solution of the as prepared $\mathrm{NP}$ followed by heating at $140{ }^{\circ} \mathrm{C}$ overnight. For the corresponding powder, typically, $0.01 \mathrm{~g}$ was sonicated in $20 \mathrm{ml}$ toluene or chloroform for an hour and the grid was prepared as mentioned above. The X-ray powder patterns were obtained on a PAD V Scintag instrument $(\mathrm{Cu} \mathrm{K} \alpha$ radiation $\lambda=1.5418 \AA ̊$ ) equipped with a graphite monochromator. Data were collected in a step scan mode between 20 and $80^{\circ} 2 \theta$, with a step size of $0.02^{\circ}$. FTIR data was obtained using a Shimadzu IR Prestige 21 equipped with a diffuse reflectance accessory. The silicon powder was mixed with the $\mathrm{KBr}$ using a 1:100 molar ratio dilution of the sample in the $\mathrm{KBr}$ matrix. The IR measurements were performed in air. Photoluminescence spectra of the nanoparticles in chloroform have been obtained on a FluoroMax-3P fluorometer.

\section{RESULTS}

The size distribution of nanoparticles obtained from the liquid and the solid phase are given in Figure 1. The TEM images obtained from the liquid phase obtained in the investigated solvents are presented in Figure 2. The FTIR spectra of the black hydrophobic solid obtained form the DME synthesis before and after wash are shown in Figure 3. This FTIR data demonstrates the partial hydrogen termination of the nanoparticles before as well as after wash. Also, from this Figure one can observe that the solvent is partially removed.

Figure 4 presents the EDX spectra of the silicon nanoparticles obtained as the solid phase in the DOE synthesis. This spectrum along with the X-ray powder diffraction data confirms that the solid powder consists of silicon.

The photoluminescence spectra (excitation and emission) obtained from the liquid phase product obtained from the DME synthesis after solvent evaporation and re-dispersion in chloroform are provided in Figure 5. 

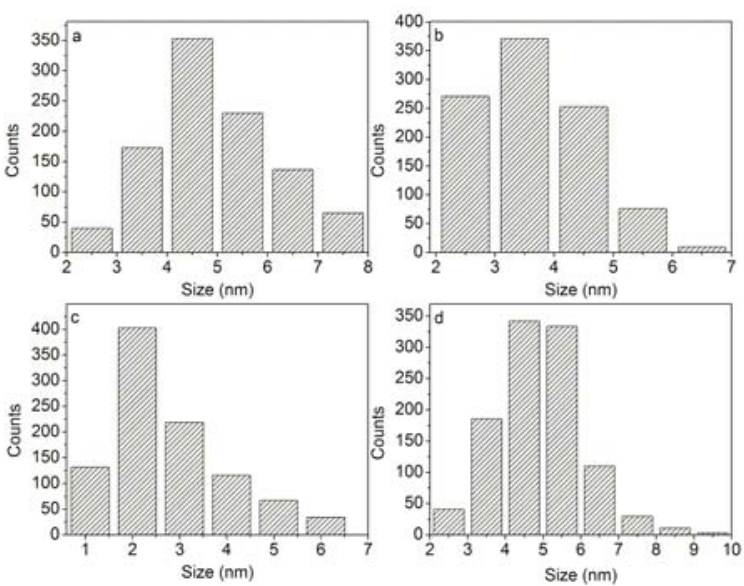

Figure 1. Size distribution for the nanoparticles obtained from the products of the solvents, DOE (a) liquid (b) solid and in DME (c) liquid (b) solid.

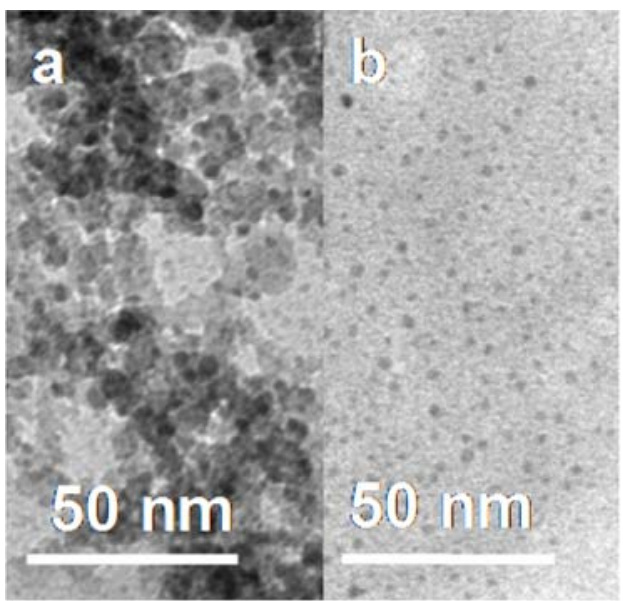

Figure 2. TEM images for nanoparticles obtained in the final solution of the reaction in a) DOE and b) DME.

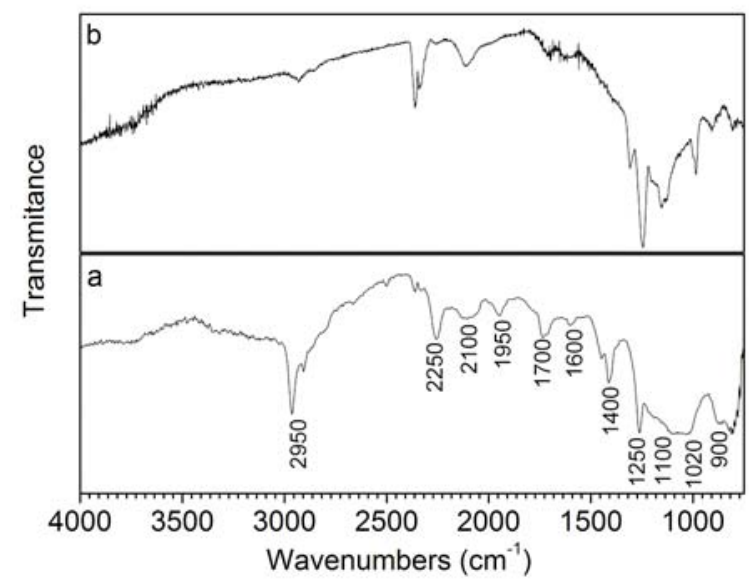

Figure 3. FTIR spectra for Si nanoparticles obtained in DME (a) before wash and (b) after wash.

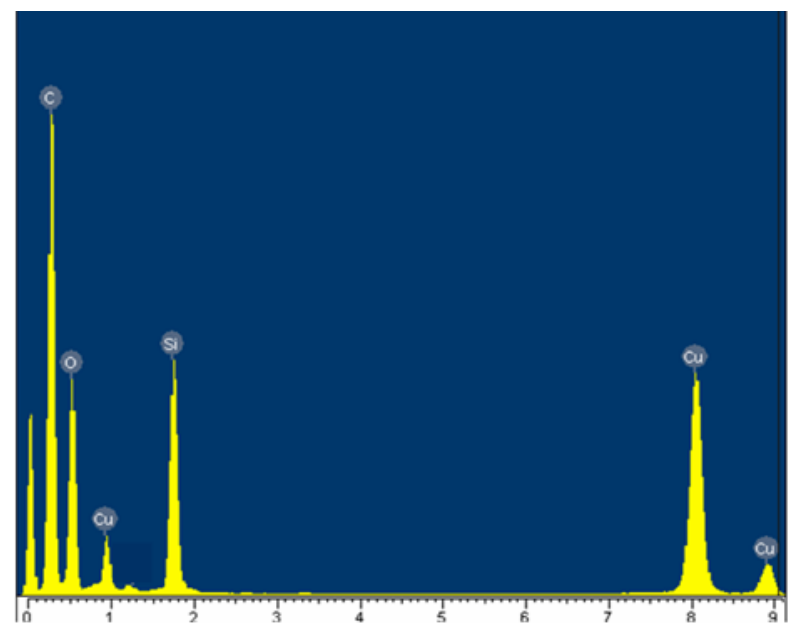

Figure 4. EDS spectra for the silicon for the nanoparticles obtained in DOE after wash.

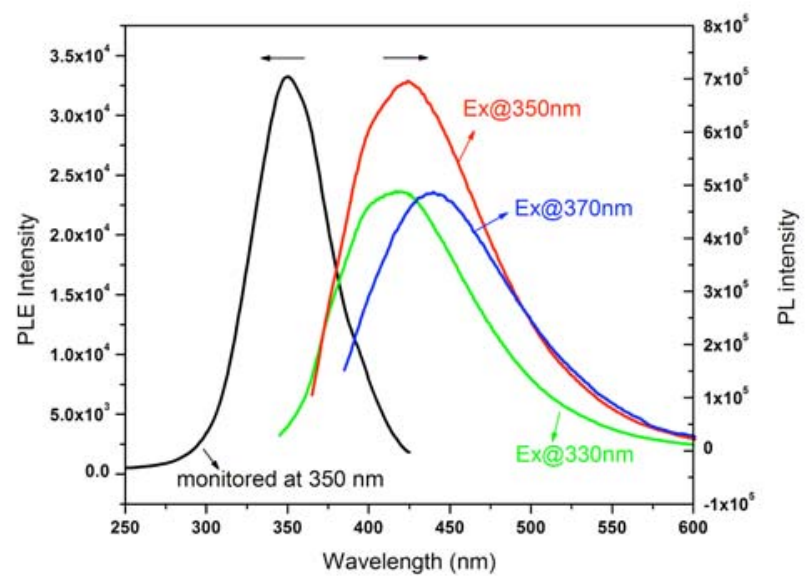

Figure 5. Photoluminescence spectra (excitation monitored at $350 \mathrm{~nm}$ and emission at exciting wavelengths of 330,350 , and $370 \mathrm{~nm}$ ) of the silicon nanoparticles present in the solution prepared in DME, dissolved in chloroform. 